\section{BMJ Open} Ophthalmology

\title{
Diabetic retinopathy screening in persons with mental illness: a literature review
}

\author{
Elinor Rhian Bradley (D) ,' Vijay Delaffon ${ }^{2}$
}

To cite: Bradley ER, Delaffon V. Diabetic retinopathy screening in persons with mental illness: a literature review. BMJ Open Ophthalmology 2020;5:e000437. doi:10.1136/ bmjophth-2020-000437

- Additional material is published online only. To view please visit the journal online (http://dx.doi.org/10.1136/ bmjophth-2020-000437).

Received 27 January 2020 Revised 30 April 2020 Accepted 1 May 2020

\section{Check for updates}

(C) Author(s) (or their employer(s)) 2020. Re-use permitted under CC BY-NC. No commercial re-use. See rights and permissions. Published by BMJ.

${ }^{1}$ Ashford Community Mental Health Trust, Kent and Medway NHS and Social Care Partnership Trust, Ashford, UK

${ }^{2}$ Willow Suite, Kent and Medway NHS and Social Care Partnership Trust, Dartford, UK

Correspondence to Dr Elinor Rhian Bradley; elinor. bradley@nhs.net

\section{ABSTRACT}

People living with severe mental illness (SMI) have an increased risk of developing diabetes and are less likely to spontaneously report physical health concerns; they may therefore derive greater benefit from attending screening to prevent diabetic retinopathy.

We conducted a literature review to consider the uptake of diabetic retinopathy screening (DRS) in people with mental illness.

People with a diagnosis of SMI and those with selfreported mental ill-health have reduced attendance at DRS, within the context of poorer compliance with general diabetic care. Anxiety and depression were noted as barriers in attending DRS.

People living with SMI require additional support to benefit from preventative health programmes such as DRS.

Further research could support a better understanding of barriers to attendance, allowing effective support systems to be developed.

\section{INTRODUCTION}

Severe mental illness (SMI) includes schizophrenia and its related conditions and bipolar disorder, along with depressive and anxiety disorders if associated with considerable functional impairment. People with schizophrenia and bipolar disorder face one of the greatest health inequality gaps in England, with their life expectancy being 10-20 years lower than the general population. ${ }^{1}$ The rate of all-cause mortality in those with bipolar disorder is 1.77 times the general population's and in those with schizophrenia is 2.08 times greater. ${ }^{1}$ Such findings are replicated within the UK. ${ }^{2}$ These discrepancies are explained not only by increased rates of suicide, but also by natural causes including disorders of the circulatory, digestive, neurological, respiratory and endocrine systems. ${ }^{3}$

The worldwide adult prevalence of the endocrine disorder, diabetes, was estimated as $4 \%$ in 1995 and is predicted to rise to $5.4 \%$ by 2025. ${ }^{4}$ Schizophrenia is itself associated with high rates of insulin resistance, this being true for even antipsychotic-naive patients. ${ }^{5}$ The prevalence of diabetes in people with schizophrenia is reported as $10.8 \%$ with a lifetime prevalence of $14.9 \% .^{6}$ The additional risk of diabetes posed by antipsychotic treatment, in particular second generation antipsychotics, is widely acknowledged ${ }^{7-9}$; olanzapine ${ }^{10}$ and clozapine $^{11}$ carrying particular risks. People with mood disorders are also at increased risk of developing diabetes ${ }^{12} 13$ and depression is itself associated with poorer glycaemic control in people with diabetes. ${ }^{14}$

In addition to an increased burden of physical morbidity, people with SMI are less likely to spontaneously report physical symptoms, ${ }^{15}$ have greater difficulties in accessing medical care $^{16}$ and receive suboptimal levels of medical care in both psychiatric and medical settings. ${ }^{17}$

Individuals with SMI may therefore derive a greater benefit from attending preventative health programmes. Current UK adult population based screening programmes include breast, cervical and bowel cancer, abdominal aortic aneurysm and diabetic retinopathy (DR). ${ }^{18}$ However compliance with cancer screening in patients with SMI is suboptimal ${ }^{19}$; women with SMI are less likely to have a cervical smear test ${ }^{20}$ and attend mammography. ${ }^{21}$

People with diabetes are at risk of developing the microvascular complication of sight-threatening DR, this is especially true for those with a long duration or poorly controlled diabetes. ${ }^{22}$ The overall prevalence of DR is estimated as $34.6 \%,{ }^{23}$ ranging from $11 \%$ to $77 \%$ in type 1 , and $3.1 \%-68 \%$ in type 2 diabetes. ${ }^{24}$ Associated with DR is significant morbidity, being the leading cause of blindness in England and Wales in 1999-2000, and the second in $2009-2010$ (14.4\% of blindness certifications) ${ }^{25}$ This decline may be secondary to improved glycaemic control ${ }^{26} 27$ alongside national DRS programmes which support early detection and timely treatment of retinopathy and can prompt optimisation of glycaemic control. ${ }^{22}$

The UK DRS programme was implemented in 2003 and was the first national programme 
available to all people with diabetes over the age of $12,{ }^{27}$ who are not already receiving ophthalmology care and do not meet exclusion criteria such as being terminally ill. ${ }^{28}$ Retinopathy screening in England is overseen by the National Health Service (NHS) Diabetic Eye Screening Programme (NDESP) and is delivered by a range of locally commissioned digital photography providers, in a variety of permanent and mobile centres. Screening results are generally sent to primary care providers within 6 weeks, with individuals being either recalled for annual screening, invited for more frequent surveillance or referred to hospital ophthalmology services depending on the results. ${ }^{22}$ The NDESP offered screening to 2700774 people with diabetes in England in 2017-2018, of whom 2232797 attended; an uptake rate of $82.7 \% .^{29}$

Given the poorer utilisation of cancer screening programmes by people with SMI,${ }^{19-21}$ we aimed to carry out a literature review of studies reporting on the utilisation of DRS among people with mental illness.

\section{Materials and methods}

A review of literature was conducted on the uptake of DRS in people with diabetes who also have a SMI (psychosis, bipolar disorder, along with depression and anxiety).

Inclusion criteria were published primary research studies, quantitative and qualitative, dating from 2003 (the inception of systematic DRS globally) to April 2019. The scope of the study was not restricted to mental illnesses meeting recognised diagnostic classification criterion. There were no language restrictions or restrictions placed on demographic characteristics or the type and duration of diabetes.

Excluded from this review was primary research relating to people with diabetes with mental disorders not considered an SMI, studies carried out prior to 2003 and unpublished research due to restricted resources.

We conducted searches of EMBASE, CINAHL, Medline, Psycinfo and PubMed electronic databases from 2003 until April 2019. We used the following keywords: 'diabetic eye screening' OR 'diabetic retinopathy screening' AND 'mental illness' OR psychiatr* OR depression OR mood OR anxiety OR SMI OR schizophrenia OR psychosis.

The electronic database search was supplemented by full-text searches of Google scholar, and hand searching of the journals: British Medical Journal, British Journal of Psychiatry and the British Journal of Ophthalmology. References of key articles were also searched.

Identified papers were assessed as to their meeting inclusion criteria independently by both authors. Studies were reviewed to extract data regarding the study's aim and design, the setting and participants, methods, outcomes and limitations. See figure 1.

\section{RESULTS}

Four North American cross-sectional studies considered the uptake of DRS in people with diabetes and a comorbid mental health issue (table 1).

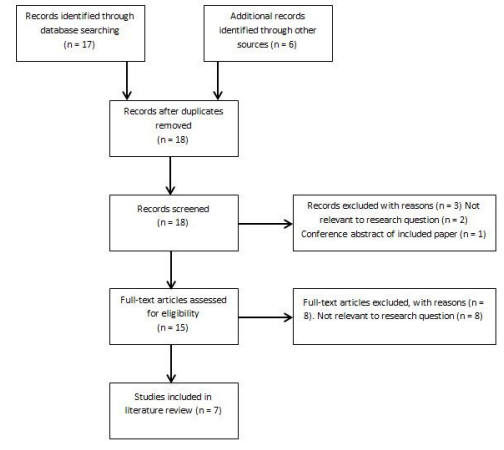

Figure 1 Diagram of study selection.

Paksin-Hall ${ }^{30}$ et al considered variables that affect DRS attendance. Data analysed originated from a national random telephone survey, the Behavioural Risk Factors Surveillance System. Fifty-two thousand three hundred and eighty-six individuals with diabetes self-reported when they had last received DRS and whether they had experienced less than 14 or 14 or more 'mentally unhealthy' days in the past 30 days. Attendance at DRS within the last year was reported by $64 \%$ of those with 14 or more 'mentally unhealthy' days $(\mathrm{n}=3203)$ compared with $73.1 \%$ of those with less than $14(\mathrm{n}=20436)$. Individuals had significantly increased odds of undergoing DRS within the last year if they had less than 14 'mentally unhealthy' days in the past 30 days (adjusted OR (AOR) of $1.22,95 \%$ CI 1.04 to 1.41 ).

Goldberg $e t a l^{31}$ conducted interviews with and reviewed medical notes of 300 people with type 2 diabetes, who were either attending an urban mental health centre or a closely located primary care centre. Of the 300 participants, $201 \mathrm{had}$ an SMI (100 schizophrenia, $101 \mathrm{mood}$ disorder) and 99 had no SMI (psychiatric treatment within the year being an exclusion criterion). Compliance with six diabetic care indicators within the last year was assessed: glycosylated haemoglobin, lipid profile, blood pressure, urine protein measurement, DRS and foot examination. The cohort with SMI were compliant with significantly less of all six diabetic care indicators, with only $56 \%$ of SMI patients meeting all six performance measures, compared with $77 \%$ in the cohort without SMI; DRS attendance rates were $80 \%$ and $94 \%$ respectively (AOR 0.26, p 0.008).

Two national studies of North American veterans were reviewed. Kilbourne et $a l^{32}$ conducted a study of 7514 non-institutionalised veterans who had a International Statistical Classification of Diseases and Related Health Problems 9th revision (ICD-9) based SMI diagnosis on the Veterans Affairs National Psychosis Registry, were subject to an annual external review process of medical care and whose care facility had submitted data for the Veterans Affairs Mental Health Programme Survey; a service organisation review with colocated care being defined as occurring within the mental health clinic itself. Attendance at DRS within the last year was $83 \%$ $(\mathrm{n}=814)$. Patients with diabetes in colocated services were less likely to attend DRS, although this was not statistically 
Table 1 Overview of DRS attendance in people with mental health issues

\begin{tabular}{|c|c|c|c|c|c|c|c|c|}
\hline Study & Study design & $\begin{array}{l}\text { Mental health } \\
\text { issue }\end{array}$ & DRS attendance & $\mathbf{N}$ & $\begin{array}{l}\text { Age } \\
\text { (years) }\end{array}$ & Ethnicity & OR $(95 \% \mathrm{Cl})$ & Country \\
\hline $\begin{array}{l}\text { Paksin- } \\
\text { Hall et } a l^{\beta 0}\end{array}$ & $\begin{array}{l}\text { Observational/cross } \\
\text { sectional }\end{array}$ & $\begin{array}{l}14 \text { or more } \\
\text { 'mentally } \\
\text { unhealthy' } \\
\text { days in past } \\
30 \text { days }\end{array}$ & $\begin{array}{l}64 \% \text { in cohort } \\
\text { with } 14 \text { or } \\
\text { more mentally } \\
\text { unhealthy days }\end{array}$ & 52386 & $\begin{array}{l}18-341.8 \% \\
35-5420 \% \\
55-6428.2 \% \\
>6550 \%\end{array}$ & $\begin{array}{l}\text { White } 55.8 \% \\
\text { Black/African- } \\
\text { American } \\
9.8 \% \\
\text { Asian } 5.9 \% \\
\text { Other } 28.6 \%\end{array}$ & $\begin{array}{l}\text { Of attending DRS } \\
\text { if }<14 \text { mentally } \\
\text { unhealthy days - } \\
\text { adjusted } 1.22 \\
(1.04 \text { to } 1.41)\end{array}$ & $\begin{array}{l}\text { North } \\
\text { America }\end{array}$ \\
\hline $\begin{array}{l}\text { Goldberg } \\
\text { et } a \beta^{31}\end{array}$ & $\begin{array}{l}\text { Observational/cross } \\
\text { sectional }\end{array}$ & $\begin{array}{l}\text { SMI } \\
\text { (schizophrenia } \\
\text { or major mood } \\
\text { disorder) }\end{array}$ & $\begin{array}{l}80 \% \text { in SMI } \\
\text { cohort }\end{array}$ & 300 & $\begin{array}{l}50.1 \text { (mean)- } \\
\text { in SMl cohort }\end{array}$ & $\begin{array}{l}\text { White } 49 \% \\
\text { Other } 51 \% \\
\text { In SMl cohort }\end{array}$ & $\begin{array}{l}\text { Of attending DRS } \\
\text { if SMI present- } \\
\text { adjusted } 0.26 \\
(0.09 \text { to } 0.7)\end{array}$ & $\begin{array}{l}\text { North } \\
\text { America }\end{array}$ \\
\hline $\begin{array}{l}\text { Kilbourne } \\
\text { et }\left.^{32}\right|^{32}\end{array}$ & $\begin{array}{l}\text { Observational/cross } \\
\text { sectional }\end{array}$ & SMI (ICD-9) & $\begin{array}{l}83 \% \text { in this } \\
\text { SMl cohort }\end{array}$ & 7514 & 56.4 (mean) & $\begin{array}{l}\text { African- } \\
\text { American 28\% } \\
\text { Other } 72 \%\end{array}$ & $\begin{array}{l}\text { Of attending } \\
\text { DRS if comorbid } \\
\text { anxiety/PTSD- } \\
1.34 \text { (1.01 to } 1.77)\end{array}$ & $\begin{array}{l}\text { North } \\
\text { America }\end{array}$ \\
\hline $\begin{array}{l}\text { Frayne et } \\
\mathrm{al}^{33}\end{array}$ & $\begin{array}{l}\text { Observational/cross } \\
\text { sectional }\end{array}$ & $\begin{array}{l}\text { Mental health } \\
\text { condition } \\
\text { (DSM IV/ } \\
\text { ICD-9) }\end{array}$ & $\begin{array}{l}57.8 \% \text { in } \mathrm{MHC} \\
\text { cohort }\end{array}$ & 313586 & $\begin{array}{l}<5536.9 \% \\
55-6420.9 \% \\
65-7426.6 \% \\
>75 \\
15.6 \%-\text { in } \\
\text { MHC cohort }\end{array}$ & $\begin{array}{l}\text { White } 73.4 \% \\
\text { African- } \\
\text { American } \\
17.6 \% \\
\text { Other } 6.8 \% \\
\text { In MHC cohort }\end{array}$ & $\begin{array}{l}\text { Of not attending } \\
\text { DRS if MHC } \\
\text { present-adjusted } \\
1.07(1.05 \text { to } 1.08)\end{array}$ & $\begin{array}{l}\text { North } \\
\text { America }\end{array}$ \\
\hline
\end{tabular}

DRS, diabetic retinopathy screening; MHC, mental health conditions; PTSD, post-traumatic stress disorder; SMI, severe mental illness.

significant (OR 0.77, CI 0.54 to 1.11). Having a comorbid diagnosis of anxiety or post-traumatic stress disorder significantly increased the likelihood of people with SMI attending DRS (OR 1.34, $\mathrm{p}<0.05)$.

Frayne et $a l^{33}$ conducted a study of 313586 noninstitutionalised Veteran Health Administration patients with diabetes, whose health facility transmitted data to a central diabetes database. Mental health and primary care experts categorised mental health conditions (MHC) into 10 categories based on Diagnostic and Statistical Manual ofMental Disorders, fourth edition (DSM IV) and ICD-9 criteria. An MHC was present in $24.5 \%$ $(\mathrm{n}=76799)$ with the most common diagnoses being depression (15.5\%), anxiety (12\%), substance misuse $(5.8 \%)$ and psychosis $(5.3 \%)$. Failure rates to attend DRS were greater in the MHC group with $42.2 \%$ lacking DRS (compared with $41 \%$ in those without a MHC), this was true for other diabetic performance measures. Patients with diabetes and an MHC were significantly more likely not to meet care standards for DRS (AOR 1.07, CI 1.05 to 1.08), glycosylated haemoglobin testing (AOR of 1.23, CI 1.21 to 1.26 ) and lipid testing (AOR 1.25, CI 1.23 to 1.28$)$. Disparities were magnified in patients with psychotic, manic, substance-misuse and personality disorders. The percentage not meeting diabetic care standards was found to increase as the number of MHCs increased from zero to six, demonstrating a dose-response effect.

Three studies reported on mental health related barriers to attending DRS (table 2).

$\mathrm{Lu}$ et $a l \mathrm{~s}^{34}$ cross-sectional survey was administered to a convenience sample of 110 adults with diabetes attending a North American urban health centre, along with staff $(n=55)$. While $93 \%$ of patients were aware of the potential for significant visual impairment secondary to diabetes, only $55 \%$ had received DRS in the last year. No barriers were encountered in 31\%, 26\% reported one barrier and $44 \%$ reported two or more. The most common self-reported barriers were financial problems

\begin{tabular}{|c|c|c|c|c|c|c|c|}
\hline Study & Study design & $\begin{array}{l}\text { DRS } \\
\text { attendance }\end{array}$ & $\mathbf{N}$ & Age (years) & Ethnicity & $\begin{array}{l}\text { Mental health related } \\
\text { barriers to attending DRS }\end{array}$ & Country \\
\hline Lu et $a l^{34}$ & $\begin{array}{l}\text { Observational/cross } \\
\text { sectional }\end{array}$ & $55 \%$ & 165 & 54 (mean) & $\begin{array}{l}\text { Hispanic } 70 \% \\
\text { African-American 27\% } \\
\text { Other 3\% }\end{array}$ & Depression (22\%) & $\begin{array}{l}\text { North } \\
\text { America }\end{array}$ \\
\hline Liu et $a l^{35}$ & $\begin{array}{l}\text { Qualitative (semi } \\
\text { structured interview) }\end{array}$ & Not stated & 29 & 67 (mean) & White $100 \%$ & $\begin{array}{l}\text { Anxiety, negative self- } \\
\text { perception, lack of self- } \\
\text { efficacy }\end{array}$ & $\begin{array}{l}\text { North } \\
\text { America }\end{array}$ \\
\hline $\begin{array}{l}\text { Strutton } \\
\text { et } \mathrm{a} /{ }^{37}\end{array}$ & $\begin{array}{l}\text { Qualitative (unstructured } \\
\text { interview) }\end{array}$ & $84 \%$ & 296 & $\begin{array}{l}12-3412.8 \% \\
35-5431 \% \\
55-7439.9 \% \\
>7515.9 \%\end{array}$ & $\begin{array}{l}\text { White } 36.4 \% \\
\text { Black/black British 5.8\% } \\
\text { Asian/Asian British 19\% } \\
\text { Mixed 1.6\% } \\
\text { Unknown 37.2\% }\end{array}$ & Anxiety & UK \\
\hline
\end{tabular}

DRS, diabetic retinopathy screening. 
$(26 \%)$ and depression $(22 \%)$. There was no association found between the number of reported barriers and attendance rates, with those reporting no barriers failing to show increased screening attendance; no statistical significance was reported. A statistically significant divergence was found between the barriers perceived by patients and staff, with staff rating financial problems and depression as less important.

Liu $e$ t $a l^{35}$ conducted a qualitative study with purposive sampling of individuals who had previously expressed an interest in research. This resulted in the recruitment of 20 adults with type 2 diabetes to whom a semi-structured interview was administered, nine primary care providers were also interviewed. The sample size was noted to be sufficient to reach informational redundancy. The interviews were audiotaped, transcribed verbatim and emerging themes from transcript analysis were verified by multiple members of the research team. Environmental, social and individual factors were identified. Environmental factors included long distances to obtain healthcare. Social factors included perceived judgement from others and a lack of trust in health practitioners. Individual factors included that limited 'time, energy and resources' led to the prioritisation of acute rather than preventative medical care, along with cost of services and limited health literacy/education. The effect of emotional states on attendance was variable with anxiety related to visual loss prompting attendance in one patient, while another avoided screening due to fear of receiving bad news. Negative self-perception and a lack of self-efficacy were found to impact negatively on attendance.

Strutton $e t a l^{36}$ considered reasons for non-attendance at DRS in the UK population. This was a service evaluation of an urban DRS programme with an uptake rate of $84 \%$. Non-attenders $(n=296)$ were defined as having 'never' attended eye screening despite being registered with the screening database for at least 18 months. Members of the screening programme contacted non-attending patients an unlimited number of times by phone. Findings were triangulated with clinical notes and by contacting primary care providers. A thematic framework analysis categorised explanations into patient and system level factors. Patient level factors included being anxious (most commonly of mydriatic eye drops), generalised dis-engagement with their diabetic care, misinformation about screening and having other commitments. Systemlevel factors included miscommunication about patients' residences and practical problems in attending.

\section{DISCUSSION}

A literature review was conducted to allow both quantitative and qualitative studies to be considered, these being complementary in identifying and attempting to explain variance in DRS attendance in persons with and without mental illness. The seven eligible studies involved 84313 individuals with a mental illness meeting ICD-9 diagnostic criteria, 201 individuals with an otherwise confirmed mental illness and 52653 individuals with subjectively defined mental health symptoms. Five studies were quantitative and two were qualitative in design, all the former being cross-sectional surveys. Study size ranged from 29 to 313586 participants, and settings ranged from single centres to national surveys. The studies included national, rural and urban populations. All but one was conducted in North America and two North American studies were limited to veterans.

DRS in individuals with a recognised mental health diagnosis, compared with those without, was considered in two studies, ${ }^{31}{ }^{33}$ both reporting reduced compliance with retinopathy screening in the context of reduced levels of compliance with overall diabetic care indicators. The disparity was greater in those with psychotic and manic disorders, and a correlation was observed between the number of MHCs present and failure in meeting diabetic care standards. ${ }^{33}$ One study identified similar discrepancies in DRS attendance between individuals with and without subjectively defined mental ill-health. ${ }^{30}$

Mental health related barriers to screening were noted in three studies. Anxiety appeared to have a variable effect on DRS attendance. It was perceived as a barrier in both a white rural North American cohort who were engaged with health services and had expressed an interest in research, ${ }^{35}$ and within an urban British mixed-ethnic cohort of DRS non-attenders. ${ }^{37}$ The anxiety described was not identifiable as a mental health diagnosis but was linked to health and screening issues for example in relation to dilating eye drops ${ }^{37}$ and coping with bad news. ${ }^{35}$ However anxiety had the opposite effect in other individuals, with anxiety related to visual loss prompting adherence. ${ }^{35}$ Kilbourne et al noted that a comorbid ICD-9 anxiety disorder diagnosis within the context of a single provider funded system supported DRS attendance. ${ }^{32}$ Self-reported depression was reported as the second most common barrier in a cohort of health centre attenders. ${ }^{34}$ Cognitions associated with depression such as a lack of self-efficacy were also reported as barriers. ${ }^{35}$ Individuals meeting the diagnostic criteria for a depressive disorder may potentially experience their burden of symptoms as an even greater barrier. No evidence was found for a dose response relationship between the numbers of barriers reported and non-attendance at screening. ${ }^{34}$ However while the survey was derived from available literature and pilot tested, the absence of this expected relationship raises the potential for the presence of additional unknown barriers.

Limitations included the small number of identified studies and that the broad inclusion criteria resulted in heterogeneous studies which were not easily comparable. Some studies may not have been identified due to chosen search keywords and relevant unpublished studies would have been overlooked. The primary research itself posed some limitations. Most of the studies were conducted in North America impacting on the generalisability of findings to the UK population; it is possible that DRS uptake may be greater in the UK where it is offered free at the point of delivery. It is possible that studies 
of veterans ${ }^{32} 33$ may be more relevant to the UK population as the Veteran Health Administration is a single provider funded system, as is the NHS. While the demographic characteristics of cohorts varied from being $100 \%$ white $^{35}$ to $97 \%$ black and minority ethnic, ${ }^{34}$ overall the samples represented a broad range of individuals which may enhance the generalisability of the findings. Selection bias may exist where participants are actively engaged with receiving health care, ${ }^{31} 323435$ express an interest in research ${ }^{35}$ or are recruited via telephone land lines. ${ }^{37}$ Positively two study samples included patients disengaged with receiving health care ${ }^{33} 37$ which may better represent the population of interest. Potential recall bias due to self-reporting of non-defined mental health symptoms was noted. ${ }^{30} 3435$ Low response rates $(57 \%)$ may introduce responder bias. However, in view of the nature of this sample a low response rate would be expected. ${ }^{37}$ Interviews conducted by DRS staff may have introduced interviewer bias, especially as responses were not recorded verbatim. ${ }^{37}$ Provider bias was considered when healthcare provider's response rates were not stated. ${ }^{37}$ Recognised criteria were used for mental health diagnosis in two studies ${ }^{32}{ }^{33}$; while increasing validity and reliability this may be at the expense of under-detecting mental health issues with true variations being diluted.

In conclusion the SMI population is at a greater risk of diabetes and hence its complications. ${ }^{5914}$ While national DRS programmes reduce avoidable visual loss, ${ }^{25}$ patient attendance is imperative in this process. A key finding of this review is that, people with diabetes who also have a formally diagnosed SMI or self-reported mental ill-health have reduced attendance at DRS within the context of poorer compliance with general diabetic care. This remains true in diverse populations.

The review has provided a tentative understanding of the impact that mood and anxiety can have on individuals accessing DRS. The correlation between the number of MHCs present and DRS non-attendance ${ }^{33}$ suggests that additional mental health symptoms have a cumulative effect and bring potentially different barriers. It seems clear that a prerequisite for DRS attendance is an individual having trust in both healthcare processes and practitioners, and that suspiciousness related to psychosis may contribute to individuals not seeking medical care. ${ }^{36}$ Limited insight associated with schizophrenia also impacts negatively on engagement with health professionals. ${ }^{38}$ Another prerequisite for preventative healthcare attendance is an individual having sufficient hope for their future and a sense of self-efficacy, these being challenging domains in a range of mental illnesses. Cognitive impairment also contributes to people with SMI not seeking medical care, ${ }^{36}$ with both schizophrenia ${ }^{3940}$ and bipolar disorder $^{41}$ being associated with cognitive impairment and impaired executive function throughout the course of the illness.

Further quantitative and qualitative research, in particular within the UK population, would support a greater understanding of DRS attendance and barriers to attendance in those with mental illness. Anxiety is often a poorly defined concept in research to date, and its role as both a barrier and facilitator of DRS requires further consideration in particular. This would allow solutions, which are perceived as helpful by individuals with mental illness, to support their accessing DRS and other preventative health strategies.

Contributors Both authors made substantial contributions to the conception, design, acquisition of data and analysis of the work. Both authors were responsible for drafting and revising the work, and approving the final version to be published. Both authors are accountable for all aspects of the integrity of the work.

Funding The authors have not declared a specific grant for this research from any funding agency in the public, commercial or not-for-profit sectors.

Competing interests None declared.

Patient consent for publication Not required.

Provenance and peer review Not commissioned; externally peer reviewed.

Open access This is an open access article distributed in accordance with the Creative Commons Attribution Non Commercial (CC BY-NC 4.0) license, which permits others to distribute, remix, adapt, build upon this work non-commercially, and license their derivative works on different terms, provided the original work is properly cited, appropriate credit is given, any changes made indicated, and the use is non-commercial. See: http://creativecommons.org/licenses/by-nc/4.0/.

\section{ORCID iD}

Elinor Rhian Bradley http://orcid.org/0000-0003-3088-5439

\section{REFERENCES}

1 Laursen TM. Life expectancy among persons with schizophrenia or bipolar affective disorder. Schizophr Res 2011;131:101-4.

2 Hayes JF, Marston L, Walters K, et al. Mortality gap for people with bipolar disorder and schizophrenia: UK-based cohort study 20002014. Br J Psychiatry 2017;211:175-81.

3 Brown S, Inskip H, Barraclough B. Causes of the excess mortality of schizophrenia. Br J Psychiatry 2000;177:212-7.

4 King H, Aubert RE, Herman WH. Global burden of diabetes, 19952025: prevalence, numerical estimates, and projections. Diabetes Care 1998;21:1414-31.

5 Ryan MCM, Collins P, Thakore JH. Impaired fasting glucose tolerance in first-episode, drug-naive patients with schizophrenia. Am J Psychiatry 2003;160:284-9.

6 Dixon L, Weiden P, Delahanty J, et al. Prevalence and correlates of diabetes in national schizophrenia samples. Schizophr Bull 2000;26:903-12.

7 Taylor DM, Barnes TR, Young AH. The Maudsley prescribing guidelines in psychiatry. John Wiley \& Sons, 2018.

8 American Diabetes Association, American Psychiatric Association, American Association of Clinical Endocrinologists, et al. Consensus development conference on antipsychotic drugs and obesity and diabetes. Diabetes Care 2004;27:596-601.

9 Sernyak MJ, Leslie DL, Alarcon RD, et al. Association of diabetes mellitus with use of atypical neuroleptics in the treatment of schizophrenia. Am J Psychiatry 2002;159:561-6.

10 Koro CE, Fedder DO, L'Italien GJ, et al. Assessment of independent effect of olanzapine and risperidone on risk of diabetes among patients with schizophrenia: population based nested case-control study. BMJ 2002;325:243.

11 Henderson DC, Cagliero E, Gray C, et al. Clozapine, diabetes mellitus, weight gain, and lipid abnormalities: a five-year naturalistic study. Am J Psychiatry 2000;157:975-81.

12 Carnethon MR, Kinder LS, Fair JM, et al. Symptoms of depression as a risk factor for incident diabetes: findings from the National health and nutrition examination epidemiologic follow-up study, 1971-1992. Am J Epidemiol 2003;158:416-23.

13 Knol MJ, Twisk JWR, Beekman ATF, et al. Depression as a risk factor for the onset of type 2 diabetes mellitus. A meta-analysis. Diabetologia 2006;49:837-45.

14 Lustman PJ, Anderson RJ, Freedland KE, et al. Depression and poor glycemic control: a meta-analytic review of the literature. Diabetes Care 2000;23:934-42.

15 Jeste DV, Gladsjo JA, Lindamer LA, et al. Medical comorbidity in schizophrenia. Schizophr Bull 1996;22:413-30. 
16 Bradford DW, Kim MM, Braxton LE, et al. Access to medical care among persons with psychotic and major affective disorders. Psychiatr Serv 2008;59:847-52.

17 Mitchell AJ, Delaffon V, Lord O. Let's get physical: improving the medical care of people with severe mental illness. Adv. psychiatr. treat 2012;18:216-25.

18 Crown Copyright. Current UK NSC recommendations. Available: https://legacyscreening.phe.org.uk/screening-recommendations.php

19 Aggarwal A, Pandurangi A, Smith W. Disparities in breast and cervical cancer screening in women with mental illness: a systematic literature review. Am J Prev Med 2013;44:392-8.

20 Martens PJ, Chochinov HM, Prior HJ, et al. Are cervical cancer screening rates different for women with schizophrenia? A Manitoba population-based study. Schizophr Res 2009;113:101-6.

21 Mitchell AJ, Pereira IES, Yadegarfar M, et al. Breast cancer screening in women with mental illness: comparative meta-analysis of mammography uptake. Br J Psychiatry 2014;205:428-35.

22 Harris M, Lead C, Warehouse V. The NHS diabetic eye screening programme: new common pathway. London: The Royal College of Ophthalmologists, Focus, 2012.

23 Yau JWY, Rogers SL, Kawasaki R, et al. Global prevalence and major risk factors of diabetic retinopathy. Diabetes Care 2012;35:556-64.

24 Sivaprasad S, Gupta B, Crosby-Nwaobi R, et al. Prevalence of diabetic retinopathy in various ethnic groups: a worldwide perspective. Surv Ophthalmol 2012;57:347-70.

25 Liew G, Michaelides M, Bunce C. A comparison of the causes of blindness certifications in England and Wales in working age adults (16-64 years), 1999-2000 with 2009-2010. BMJ Open 2014;4:e004015.

26 Diabetes Control and Complications Trial Research Group. The relationship of glycemic exposure $(\mathrm{HbA} 1 \mathrm{c})$ to the risk of development and progression of retinopathy in the diabetes control and complications trial. Diabetes 1995;44:968-83.

27 King P, Peacock I, Donnelly R. The UK prospective diabetes study (UKPDS): clinical and therapeutic implications for type 2 diabetes. $\mathrm{Br}$ $J$ Clin Pharmacol 1999;48:643-8.

28 Scanlon $\mathrm{PH}$. The English national screening programme for diabetic retinopathy 2003-2016. Acta Diabetol 2017;54:515-25.
29 Public Health England. NHS screening programmes in England 1 April 2017 to 31 March 20182019.

30 Paksin-Hall A, Dent ML, Dong F, et al. Factors contributing to diabetes patients not receiving annual dilated eye examinations. Ophthalmic Epidemiol 2013;20:281-7.

31 Goldberg RW, Kreyenbuhl JA, Medoff DR, et al. Quality of diabetes care among adults with serious mental illness. Psychiatr Serv 2007;58:536-43.

32 Kilbourne AM, Pirraglia PA, Lai Z, et al. Quality of general medical care among patients with serious mental illness: does colocation of services matter? Psychiatr Serv 2011;62:922-8.

33 Frayne SM, Halanych JH, Miller DR, et al. Disparities in diabetes care: impact of mental illness. Arch Intern Med 2005;165:2631-8.

34 Lu Y, Serpas L, Genter P, et al. Divergent perceptions of barriers to diabetic retinopathy screening among patients and care providers, Los Angeles, California, 2014-2015. Prev Chronic Dis 2016;13:E140.

35 Liu Y, Zupan NJ, Shiyanbola OO, et al. Factors influencing patient adherence with diabetic eye screening in rural communities: a qualitative study. PLoS One 2018;13:e0206742.

36 Phelan M, Stradins L, Morrison S. Physical health of people with severe mental illness: can be improved if primary care and mental health professionals pay attention to it. BMJ 2001;322:443-4.

37 Strutton R, Du Chemin A, Stratton IM, et al. System-Level and patient-level explanations for non-attendance at diabetic retinopathy screening in Sutton and Merton (London, UK): a qualitative analysis of a service evaluation. BMJ Open 2016;6:e010952.

38 Jeste DV, Gladsjo JA, Lindamer LA, et al. Medical comorbidity in schizophrenia. Schizophr Bull 1996;22:413-30.

39 Morrison G, O'Carroll R, McCreadie R. Long-Term course of cognitive impairment in schizophrenia. $\mathrm{Br} J$ Psychiatry 2006;189:556-7.

40 Bowie CR, Harvey PD. Cognitive deficits and functional outcome in schizophrenia. Neuropsychiatr Dis Treat 2006;2:531-6.

41 Martínez-Arán A, Vieta E, Colom F, et al. Cognitive impairment in euthymic bipolar patients: implications for clinical and functional outcome. Bipolar Disord 2004;6:224-32. 